\title{
Does the reflexive measurement of free PSA have a role in a tertiary cancer centre?
}

\author{
Christopher Allard, MD; ${ }^{*}$ Paul Yip, MD; ${ }^{\dagger}$ Ivan Blasutig, PhD, ${ }^{\dagger}$ Karen Hersey, RN, ${ }^{\ddagger}$ Neil Fleshner, MD, FRCSC ${ }^{\ddagger}$
}

See related article on page 321 .

\section{Abstract}

Purpose: The percent free prostate-specific antigen (PSA) may complement total PSA for prostate cancer screening, but is of no benefit for monitoring patients with previous prostate cancer diagnoses. At the Princess Margaret Hospital, a tertiary cancer centre in Toronto, Ontario, Canada, PSA values in the range 4 to $10 \mathrm{ng} / \mathrm{mL}$ prompt reflexive measurements of free PSA. We hypothesize that reflexive free PSA testing at tertiary cancer centres generates unnecessary costs as the test is often conducted on patients with previous diagnoses of prostate cancer.

Materials and Methods: We reviewed all reflexive free PSA measurements conducted on a random sample of 250 men in a 10-year period at our institution. We determined the clinical indications for the PSA tests which triggered reflexive free PSA measurements to estimate the proportion of free PSA tests that are not clinically indicated.

Results: We reviewed the 1099 reflexive free PSA measurements for the 250 subjects. Of these tests, 562 (51\%) were triggered by PSA tests ordered for screening/early detection, and 537 (49\%) for monitoring.

Conclusions: Of all reflexive free PSA tests, $49 \%$ were unnecessary. We conducted 3022 free PSA tests, at a cost of $\$ 5.84$ per test (Can\$); the tests were performed in 2009 at this institution for a total cost of $\$ 17648.48$, about $49 \%$ of which ( $\$ 8647.76$ ) likely represents unnecessary annual costs. We suggest a trial of userselectable order sets allowing physicians to choose whether to include reflexive free PSA measurements on a case-by-case basis. This policy might improve the cost-effectiveness of the PSA test at tertiary cancer centres.

Can Urol Assoc J 2010;4(5):317-320

\section{Résumé}

Objectif : Le pourcentage d'antigène prostatique spécifique (APS) libre peut compléter la mesure de I'APS total dans le dépistage du cancer de la prostate, mais il n'est d'aucune utilité pour la surveillance de patients ayant déjà reçu un diagnostic de cancer de la prostate. À I'hôpital Princess Margaret, un centre de soins oncologiques tertiaires de Toronto, en Ontario (Canada), un taux d'APS se situant entre 4 et $10 \mathrm{ng} / \mathrm{mL}$ entraîne systématiquement une évaluation des taux d'APS libre. Nous avançons I'hypothèse que la mesure de l'APS libre dans les centres de soins oncologiques tertiaires entraîne des dépenses inutiles car ce test est souvent mené chez des patients ayant déjà reçu un diagnostic de cancer de la prostate.

Matériel et méthodes : Nous avons examiné tous les cas de mesure de l'APS libre effectuée dans un échantillon aléatoire de 250 hommes sur une période de 10 ans à notre établissement. Nous avons vérifié les indications cliniques liées aux mesures de l'APS ayant entraîné une mesure de l'APS libre afin d'évaluer la proportion de ces mesures de I'APS libre qui n'étaient pas justifiées sur le plan clinique.

Résultats : Chez les 250 sujets, 1099 mesures de l'APS libre ont été effectuées. Sur ces tests, 562 (51\%) ont fait suite à des mesures de I'APS prescrites à des fins de dépistage/diagnostic précoce, et $537(49 \%)$ à des fins de surveillance.

Conclusions : De toutes les mesures de l'APS libre, $49 \%$ n'étaient pas nécessaires; 3022 tests de mesure de l'APS libre, au coût de 5,84 \$ par test, ont été effectués en 2009 à notre établissement, pour un coût total de 17648,48 , dont environ $49 \%$ - pour un montant de $8647,76 \$$ - représente selon toute apparence des dépenses inutiles. Nous suggérons d'établir une règle basée sur le jugement clinique et permettant aux médecins de choisir d'inclure ou non la mesure de l'APS libre au cas par cas. Une telle politique pourrait améliorer la rentabilité des mesures de I'APS dans les centres de soins oncologiques tertiaires.

\section{Introduction}

The measurement of prostate-specific antigen (PSA) is widely used for prostate cancer screening. High PSA values raise the suspicion of prostate cancer and may warrant further investigations. It is well-recognized that PSA is an imperfect screening test, and various tools have been implemented to aid its interpretation, including age-specific PSA cut-offs, PSA velocity, PSA density and the percent free PSA. ${ }^{1,2}$

Free PSA consists of circulating PSA which is unbound to serum proteins. Lower percent free PSA values are more suspicious for prostate cancer than higher values. ${ }^{2-7}$ Free PSA may be useful in patients with moderately elevated PSA levels in whom a high percent free PSA suggests a benign source; it may help the clinician and patient to decide whether to proceed to transrectal ultrasound (TRUS)-guided prostate biopsy. ${ }^{2,7}$

In addition to screening for prostate cancer, total PSA is used as a sensitive marker for prostate cancer recurrence 
after treatment. In this setting, only the total PSA is relevant; free PSA has no established role in post-treatment monitoring. Likewise, there is no proven utility of free PSA measurements in patients undergoing active surveillance for a known prostate cancer.

At Princess Margaret Hospital, a tertiary cancer centre in Toronto, Ontario, Canada, all PSA results in the range of 4 to $10 \mathrm{ng} / \mathrm{mL}$ prompt the reflexive measurement of free PSA as an aid for timely availability of free PSA values when this test may be clinically useful. We propose that the reflexive measurement of free PSA is often unnecessary at tertiary cancer centres, where a significant proportion of PSA tests are ordered for cancer monitoring rather than screening. By reviewing the charts of 250 patients for whom a free PSA was reflexively measured, we categorized the indications that prompted the PSA tests and estimated the proportion of reflexive free PSA tests that were not clinically indicated. This quality control study might suggest the need for a more cost-effective approach to the measurement of free PSA at tertiary centres.

\section{Methods}

Our study data were derived from a random population of men for whom free PSA was reflexively measured in a 1-year period at Princess Margaret Hospital. Princess Margaret Hospital is 1 of 3 hospitals that comprise the University Health Network in Toronto, Canada and share a central laboratory that performs total and free PSA tests.

Following research ethics board approval, a random list of 250 medical record numbers for Princess Margaret Hospital patients who had 1 or more reflexive free PSA tests was generated from the laboratory database. A chart review was conducted to extract all reflexive free PSA measurements performed on this sample of patients in the 10-year period from 2000 to 2009, and to determine the clinical indication that prompted a physician to order the total PSA test.

PSA measurements that prompted reflexive free PSA measurements were classified according to the following indications:

1. Screening/early detection; no known prostate cancer or prostatic intraepithelial neoplasia (PIN)

2. Screening/early detection; history of high-grade PIN but no known prostate cancer

3. Active surveillance (no treatment); known prostate cancer

4. Hormonal therapy, chemotherapy or post-orchiectomy

5. Post-radical prostatectomy

6. Post-external beam radiation

7. Post-brachytherapy

8. Post-high intensity focused ultrasound (HIFU)

PSA tests were classified according to the most recent indication at the time of measurement. For example, if multiple reflexive free PSA measurements were performed for a particular patient over the 10-year period, each PSA test might fall into a different category, depending on the patient's changing circumstances.

All of the above indications were further grouped according to the following general categories: (1) screening/early detection; no previous prostate cancer diagnosis (includes indications 1 and 2, above); and (2) monitoring; previous prostate cancer diagnosis (includes indications 3 to 8, above)

The financial management system at the University Health Network provided information regarding the monetary costs associated with reflexive free PSA tests.

\section{Results}

A random sample of 250 patients who received reflexive free PSA measurements was generated and their records from 2000 to 2009 were reviewed. The age of patients ranged from 45 to 93 years, with a median and mean age of 70 years and a standard deviation of 9.7 years. On average, 4.4 reflexive free PSA tests were conducted for each of the 250 patients.

A total of 1099 reflexive free PSA tests were performed for the 250 patients during the 10-year period. The top 3 indications for ordering PSA tests that prompted reflexive free PSA measurements were screening/early detection of patients with no history of prostate cancer or PIN (453, $41 \%$ ), active surveillance of patients with prostate cancer $(223,20 \%)$ and monitoring of patients on hormonal therapy or chemotherapy or post-orchiectomy (151, 13.7\%) (Fig. 1).

Tests were categorized according to the patient's most recent treatment when the PSA test was ordered. Very few test indications fall into the postoperative category (6, 5.5\%) because postoperative patients with PSA in the range 4 to $10 \mathrm{ng} / \mathrm{mL}$ usually have recurrent or advanced prostate cancers and have consequently moved on to additional treatments, including salvage radiation or hormonal therapy.

Of the 1099 free PSA measurements performed, 562 were indicated for prostate cancer screening or early detection and 537 for prostate cancer monitoring (Fig. 2).

To estimate the current unnecessary annual costs associated with reflexive free PSA measurements at this institution, the number of tests ordered in the most recent 1 -year period was reviewed. In 2009, 17386 PSA tests were ordered, of which 3022 were in the range of 4 to $10 \mathrm{ng} / \mathrm{mL}$, prompting reflexive measurements of free PSA. The cost of a single free PSA measurement is $\$ 5.84$ at our institution (all costs are listed in Canadian dollars). Our results suggest that about $49 \%$ of the reflexive free PSA tests conducted over the 10-year study period were clinically irrelevant. Assuming that $49 \%$ of the reflexive free PSA tests in 2009 were likewise irrelevant, about $\$ 8647.76$ was spent on unnecessary free PSA tests in the last year. 


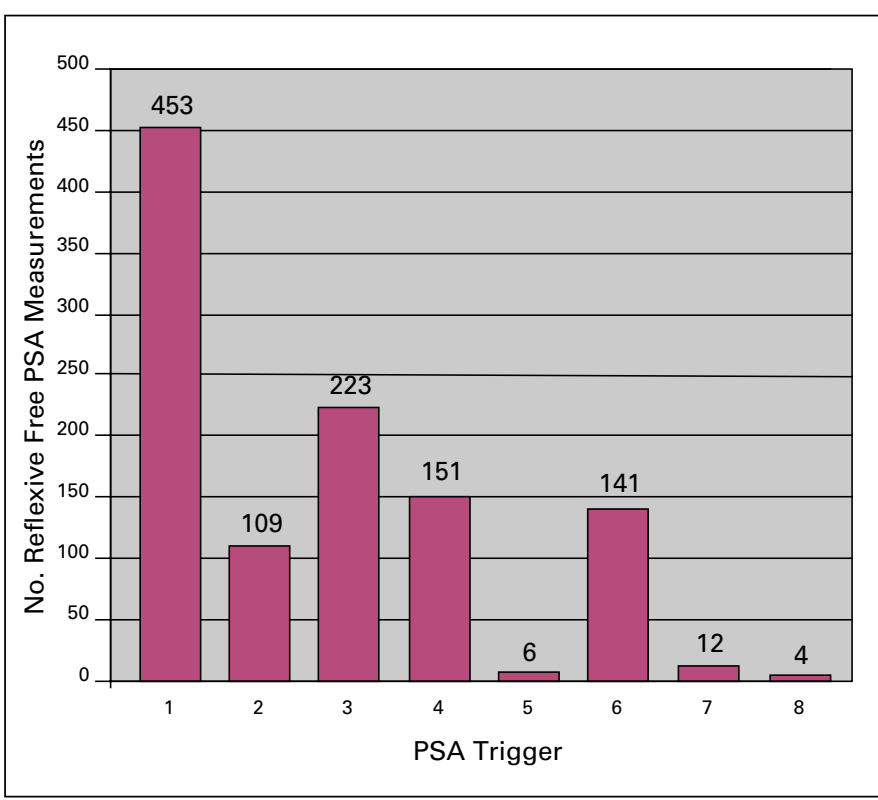

Fig. 1. Reflexive free prostate-specific antigen (PSA) measurements by PSA trigger. 1 = screening/early detection; no known prostate cancer or prostatic intraepithelial neoplasia (PIN); 2 = screening/early detection; history of high grade PIN, no known prostate cancer; $3=$ active surveillance (no treatment); known prostate cancer; $4=$ hormonal therapy, chemotherapy, or post-orchiectomy; $5=$ post-radical prostatectomy; $6=$ post-external beam radiation; 7 = post-brachytherapy; $8=$ post-high intensity focused ultrasound.

\section{Discussion}

The utility of prostate cancer screening, comprising PSA testing and digital rectal examination (DRE), is a controversial subject. Although mortality from prostate cancer has consistently fallen since the introduction of PSA screening, until recently there have been no randomized controlled trials which demonstrate a mortality benefit from screening. ${ }^{8}$

Preliminary results from 2 large randomized controlled trials do not unambiguously settle the debate. The Prostate, Lung, Colorectal and Ovarian (PLCO) Cancer Screening Trial reports no statistically significant mortality benefit from screening with PSA and DRE during a median 11-year follow-up. ${ }^{9,10}$ The authors point to several possible confounding factors, including a high level of PSA screening in the control group and inadequate long-term follow-up.

Conversely, the European Randomized Study of Screening for Prostate Cancer (ERSPC) trial reports that screening with PSA alone was associated with a $20 \%$ relative reduction in mortality from prostate cancer during a 9-year median follow-up. ${ }^{10,11}$ Even if a mortality benefit from prostate cancer screening is ultimately demonstrated, the benefits of screening must be weighed against the risks, including complications from unnecessary biopsies and overtreatment.

Free PSA is one of several tools that may improve PSA screening. Like total PSA, the usefulness and appropriate cut-off values for percent free PSA are subject to ongoing

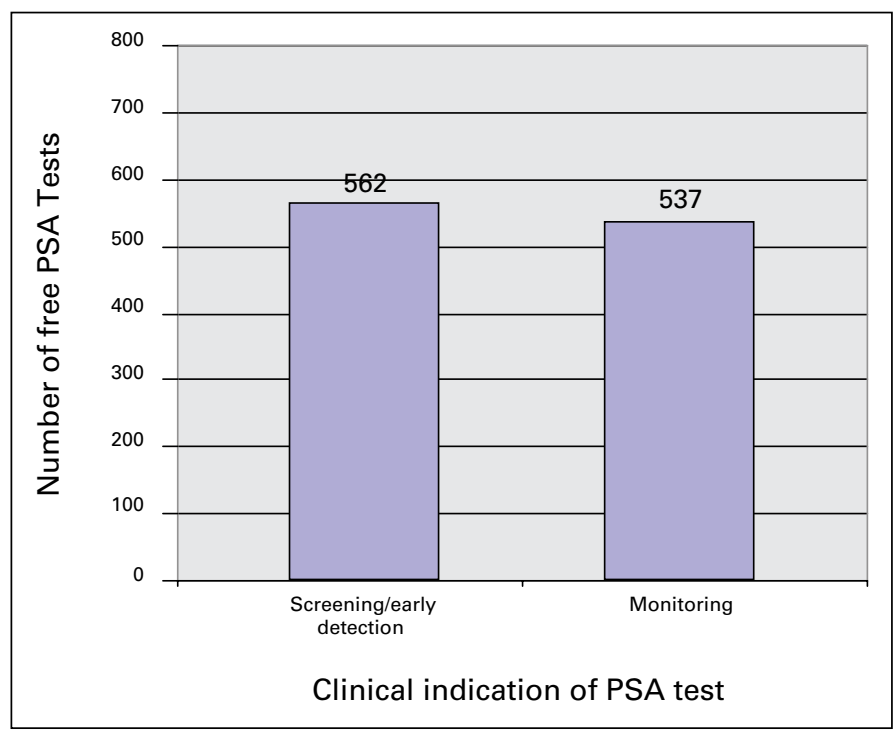

Fig. 2. Reflexive free prostate-specific antigen tests by indication.

controversy. A prospective blinded study demonstrated that using a percent free PSA cut-off of $25 \%$ in patients with total PSA 4 to $10 \mathrm{ng} / \mathrm{mL}$ detected $95 \%$ of cancers and avoided $20 \%$ of unnecessary biopsies. ${ }^{7}$ Other studies have suggested different optimal total PSA ranges for which free PSA should be used, as well as different optimal percent free PSA cutoffs. ${ }^{2,4}, 5,6,7,12$ At the University Health Network in Toronto, a total PSA in the range of 4 to $10 \mathrm{ng} / \mathrm{mL}$ prompts a reflexive free PSA measurement.

Some studies have demonstrated the usefulness of free PSA for lower total PSA values. In one retrospective study, among all patients with PSA $<3 \mathrm{ng} / \mathrm{mL}$ who underwent TRUSguided prostate biopsy because of suspicious DRE or TRUS, 9 out of 42 patients $(21 \%)$ with percent free PSA $\leq 18 \%$ had positive biopsies, while none of the 159 patients with percent free PSA $>18 \%$ had positive biopsies. ${ }^{3}$ Another study of men at higher risk for prostate cancer (African American or a first-degree relative with prostate cancer) found that $32 \%$ of men with a normal DRE and a total PSA value between 2 and $4 \mathrm{ng} / \mathrm{mL}$ with percent free PSA values $<27 \%$ had prostate cancer. ${ }^{12}$ These studies suggest that free PSA may be useful even when total PSA is outside the range of 4 to $10 \mathrm{ng} / \mathrm{mL}$.

The 250 men included in this study had a total of 1099 free PSA measurements which were measured reflexively following a total PSA result in the range of 4 to $10 \mathrm{ng} / \mathrm{mL}$. Of these, $537(49 \%)$ were triggered by prostate cancer monitoring, rather than for screening or early detection. Free PSA is of no known clinical utility for the monitoring of patients with a past or current diagnosis of prostate cancer, and hence roughly half of the free PSA measurements in this study were unnecessary.

In 2009, physicians at Princess Margaret Hospital ordered 17386 total PSA tests, of which 3022 were in the range 
Allard et al.

4 to $10 \mathrm{ng} / \mathrm{mL}$ and consequently triggered free PSA measurements. The cost of each free PSA test, which includes materials, labour and indirect costs, such as overhead and infrastructure, is $\$ 5.84$ at our institution. If $49 \%$ of these investigations were clinically unnecessary in 2009 , as they were for the 250 patients in the 10-year period studied, the total cost of unnecessary free PSA measurements at Princess Margaret Hospital in the last year was about $\$ 8647.76$. Some institutions use a PSA trigger of $2.5 \mathrm{ng} / \mathrm{mL}$, likely generating many more unnecessary free PSA tests at significant costs; using this trigger at our institution would have led to an additional 1408 reflexive free PSA tests in 1 year resulting in significant additional unnecessary costs.

\section{Conclusion}

This study demonstrates that about half of the reflexive free PSA measurements at a tertiary cancer centre, such as the Princess Margaret Hospital, may be unnecessary and costly. Furthermore, the lack of consensus on the optimum PSA range for which to order a free PSA and the ideal percent free PSA cut-offs highlight the need for clinicians and patients to consider the merits of ordering free PSA tests on a caseby-case basis.

It is our recommendation that tertiary cancer centres, such as the Princess Margaret Hospital, consider alternative approaches to the measurement of free PSA. One possibility, which might be evaluated in a small trial prior to widespread implementation, could be the inclusion of order options that allow physicians to indicate whether they would like free PSA measured if the total PSA falls within 4 to $10 \mathrm{ng} / \mathrm{mL}$. It is hoped that this policy might allow physicians to tailor the free PSA test to each patient's unique circumstances, while significantly reducing the costs associated with unnecessary reflexive free PSA measurements.

Princess Margaret Hospital, Toronto, ON *University of Toronto, Toronto, ON; 'Laboratory Medicine

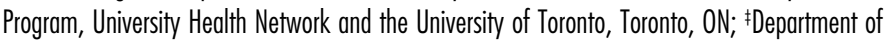
Surgical Oncology, University Health Network and the University of Toronto, Toronto, ON
Competing interests: None declared.

This paper has been peer-reviewed.

\section{References}

1. Barry MJ. Prostate-specific antigen testing for early diagnosis of prostate cancer. N Engl J Med 2001;344:1373-7.

2. Gann PH, Jing MA, Catalona WJ, et al. Strategies combining total and percent free prostate specific antigen for detecting prostate cancer: a prospective evaluation. J Urol 2002;167:2427-34.

3. Tornblom M, Norming U, Adolfsson J, et al. Diagnostic value of percent free prostate-specific antigen: retrospective analysis of a population-based screening study with emphasis on men with PSA levels less than $3.0 \mathrm{ng} / \mathrm{mL}$. Urology 1999:53:945-50.

4. Vashi AR, Wojno KJ, Henricks W, et al. Determination of the "reflex range" and appropriate cutpoints for percent free prostatespecific antigen in 413 men referred for prostatic evaluation using the AXSYM system. Urology 1997;49:19-27.

5. Luderer AA, Chen Y-T, Soriano TF, et al. Measurement of the proportion of free to total prostate-specific antigen improves the diagnostic performance of prostate-specific antigen in the diagnostic gray zone of total prostate-specific antigen. Urology 1995;46:187-94.

6. Chen YT, Luderer AA, Thiel RP, et al. Using proportions of free to total prostate-specific antigen to predict the probability of prostate cancer. Urology 1996;47:518-24.

7. Catalona WJ, Partin AW, Slawin KM, et al. Use of the percentage of free prostate-specific antigen to enhance differentiation of prostate cancer from benign prostatic disease. JAMA 1998;279:1542-7.

8. McDavid K, Lee J, Fulton JP, et al. Prostate cancer incidence and mortality rates and trends in the United States and Canada. Public Health Rep 2004;119:174-86.

9. Andriole GL, Crawford ED, Grubb RL, et al. Mortality results from a randomized prostate-cancer screening trial. N Engl J Med 2009;360:1310-9.

10. Barry MJ. Screening for prostate cancer - the controversy that refuses to die. N EnglJ Med 2009;360:1351-4.

11. Schröder FH, Hugosson J, Roobol MJ, et al. Screening and prostate-cancer mortality in a randomized European study. N Engl J Med 2009;360:1320-8.

12. Uzzo RG, Pinover WH, Horwitz EM, et al. Free prostate-specific antigen improves prostate cancer detection in a high-risk population of men with a normal total PSA and digital rectal examination. Urology 2003;61:754-9

Correspondence: Dr. Christopher Allard, c/o Karen Hersey, Princess Margaret Hospital, 610 University Ave., Room 4 - 913, Toronto, ON M5G 2M9; allardb@@mail.com 


\title{
Reflexive ordering of percent free PSA in patients: Do we need to ask the question?
}

\author{
Jean-Baptiste Lattouf, MD, FRCSC
}

See related article on page 317.

T he authors have studied the practice of "reflexive" ordering of percent free prostate-specific antigen (PSA) in patients that have a total PSA value between 4 and 10 ng. ${ }^{1}$ This ordering is standard procedure at their tertiary care centre and possibly across other centres. They conclude that nearly half of the percent free PSA measurements are probably not warranted and result in $\$ 8647.76$ of unnecessary yearly costs at their institution.

This figure may be small when one considers the global budget of a tertiary care centre, but it should be kept in mind that only one test is being analyzed here. One wonders what the cumulative cost would be if other "reflexive" laboratory tests across specialties are factored in. ${ }^{2,3}$ Further, due to the nature of the data analysis, the number of unnecessary tests is probably underestimated. Indeed, the study does not take into account the unfortunate, but common, scenarios where PSA is ordered for clinical conditions known to result in false positive values, such as in the setting of cystitis or after catheter placement. These tests would be considered screening tests since the subjects may not have a diagnosis of cancer, and therefore the tests may have been falsely deemed justified.

Asking whether a reflexive laboratory measurement is warranted in a condition as controversial and heterogeneous as prostate cancer (whether for screening or follow-up) is akin to asking whether taking a history and performing a physical are necessary to treat a patient. It is unfortunate that the authors had to ask this question, but I congratulate them for critically assessing this routine practice, and concluding what should be considered obvious by many clinicians.

Département de Chirurgie-Urologie, Centre Hospitalier de l'Université de Montréal, Montréal, QC

Competing interests: None declared.

This paper has been peer-reviewed.

\section{References}

1. Allard C, Yip P, Blasutig I, et al. Does the reflexive measurement of free PSA have a role in a tertiary cancer centre? Can Urol Assoc J 2010;4:317-20.

2. Collier CP, Clark AF, Bain J, et al. Functional testosterone: biochemical assessment of hypogonadism in men-report from a multidisciplinary workshop hosted by the Ontario Society of Clinical Chemists. Aging Male 2007;10:211-6.

3. Rowe LR, Aldeen W, Bentz JS. Prevalence and typing of HPV DNA by hybrid capture II in women with ASCUS, ASC-H, LSIL, and AGC on ThinPrep Pap tests. Diagn Cytopathol 2004;30:426-32.

Correspondence: Dr. Jean-Baptiste Lattouf, Professeur adjoint de clinique, Département de ChirurgieUrologie, Centre Hospitalier de I'Université de Montréal, 1058 Rue St-Denis, Montréal, QC H2X 3J4; fax: 514-412-7411; jean-baptiste.lattou@umontreal.ca 